\title{
Propostas de formação matemática em currículos prescritos de cursos de licenciatura em matemática na modalidade à distância
}

Proposals mathematical training in e-learning mathematics degree courses

Larissa Bonfim de Ávila ${ }^{1}$ João Ricardo Viola dos Santos ${ }^{2}$

\section{Resumo}

O objetivo deste artigo é investigar propostas de formação matemática em currículos prescritos de cursos de Licenciatura em Matemática, na modalidade a distância. Em meio a uma abordagem qualitativa de pesquisa, analisamos aspectos dessas propostas em currículos de duas universidades. Nossas análises indicam a presença de reflexões a respeito de qual matemática é necessária ou adequada para o futuro professor de matemática, bem como uma busca de articulação entre os domínios de conhecimentos pedagógico e matemático nas disciplinas.

Palavras-chave: formação matemática, currículo, educação a distância.

\section{Abstract}

The aim of this paper is to investigate proposals of mathematical preparation presented in curricula of distance education mathematics teacher education courses. Using a qualitative research approach, we analyze aspects of these proposals in the curricula of two universities. Our analyses indicate the presence of reflections on which mathematics is necessary or appropriate to prospective mathematics teachers, as well as a search for articulations between the domains of mathematical knowledge and pedagogical knowledge in the disciplines.

Keywords: mathematical preparation, curricula, distance education.

\footnotetext{
${ }^{1}$ Universidade Federal de Mato Grosso do Sul (discente) | larissabavila@gmail.com

2 Universidade Federal de Mato Grosso do Sul | joao.santos@ufms.br
} 


\section{Introdução}

Nos últimos anos, houve um crescimento de investigações a respeito da formação matemática de futuros professores de matemática em cursos de formação inicial (MOREIRA E DAVID, 2003, 2004; LINS, 2006; OLIVEIRA, 2011; VIOLA DOS SANTOS, 2012). Será que a formação matemática de professores, em cursos de formação inicial, é constituída tomando por referência sua prática profissional? Quais tópicos matemáticos os futuros professores necessitam experienciar, durante sua formação inicial, para trabalhar com a matemática escolar na Educação Básica? Qual é a matemática do professor de matemática? Essas, entre outras perguntas, ainda carecem de respostas sistematizadas. Mesmo com aumento de pesquisas nessa área, poucos direcionamentos foram delineados para reestruturações nos cursos de Licenciaturas Matemática.

Atualmente, no Brasil, os cursos de graduação na modalidade a distância são uma realidade. Desde 2006, com a implantação do Sistema Universidade Aberta do Brasil (UAB) ${ }^{3}$, o número de Licenciaturas em Matemática nessa modalidade vem crescendo com cursos de diferentes naturezas e dinâmicas de funcionamento. Atualmente, na Educação Superior, temos 88 instituições públicas, entre universidades federais, estaduais e Institutos Federais de Educação, Ciência e Tecnologia (IFETs) ${ }^{4}$.

Utilizando novas tecnologias de interação e flexibilizando os espaços e tempos, os cursos a distância oferecem possibilidades de uma formação superior para muitos brasileiros trabalhadores com poucas condições para realizarem uma graduação.

Em muitos currículos de cursos de Licenciatura em Matemática, na modalidade a distância, ocorre uma transposição da grade curricular dos cursos presenciais. Entretanto, por se tratar de um curso novo, há possibilidade de os projetos políticos pedagógicos apresentarem algumas inovações ou mesmo pequenas mudanças em relação às suas grades curriculares. Nesse ponto, estão nossas inquietações em relação às propostas de formação matemática, em currículos prescritos na modalidade da Educação a Distância.

Assim, o objetivo deste trabalho é investigar propostas de formação matemática em currículos prescritos de cursos de Licenciatura em Matemática na modalidade a distância, indagando quais as características desses cursos e quais os aspectos das propostas de formação matemática que podem ser investigados por meio de seus Projetos Políticos Pedagógicos (PPPs) ${ }^{5}$. Dessa forma, apresentamos uma análise de dois PPPs de cursos de Licenciatura em Matemática na modalidade a distância, tomando como foco algumas argumentações a respeito da formação matemática.

\section{Sobre a Formação Matemática de Professores de Matemática}

Muito se tem falado sobre os problemas que professores de matemática enfrentam nas escolas, como, por exemplo, a indisciplina dos alunos, baixa remuneração salarial, más condições de trabalho e pouco tempo para preparar suas aulas. No entanto, nesse

\footnotetext{
${ }^{3}$ Para mais informações sobre a UAB acessar: http://uab.capes.gov.br/

${ }^{4}$ Dados de 2010. Para mais informações acessar: http://uab.capes.gov.br/

${ }^{5}$ Neste texto, tomaremos como sinônimos as expressões Currículo Prescrito e Projeto Político Pedagógico.
} 
contexto, outro problema que ainda se mostra é a qualidade do conhecimento matemático dos professores que atuam na Educação Básica em sua formação inicial.

De maneira geral, o destino do futuro professor de matemática, ou seja, a sala de aula da Educação Básica, não faz parte da realidade acadêmica que ele vivencia durante sua Licenciatura em Matemática. O que queremos dizer é que as disciplinas que compõem a grade curricular da Licenciatura são estruturadas em direção oposta ao que ele vai trabalhar e conviver na sala de aula. Não há, ou há poucas, conexões entre as disciplinas consideradas de conteúdo matemático e a realidade do que é estudado nas salas de educação básica. Como Lins (2005) afirma, em relação a um possível curso de Licenciatura em Educação Matemática,

/.../ porque é, então que não dedicamos diretamente uma parte muito maior dos cursos de conteúdo matemático, nas licenciaturas, à Matemática escolar? O tempo gasto com "Matemática superior" - Análise, Estruturas Algébricas, Álgebra Linear - é grande, e é provável que siga em vista das recentes, e conservadoras, diretrizes curriculares para as Licenciaturas em Matemática. Mas com que justificativas? Não seria melhor, insisto, ensinar bem aos professores o que eles têm que ensinar, se acreditamos: (a) isso é o que eles têm que fazer e têm que estar atualizados; e (b) eles não aprenderam direito na escola? (LINS, 2005, p. 119-120).

As perguntas colocadas por Lins ainda carecem de respostas, mesmo que estas muitas vezes nos pareçam óbvias.

Os acadêmicos dos cursos de Medicina, por exemplo, estão em contato com sua realidade profissional desde o primeiro ano da faculdade. Não apenas no que diz respeito ao contato com os pacientes, mas também vivenciando realidades nas quais futuramente estarão inseridos. As disciplinas estudadas requerem estágios que coloquem em prática o que foi estudado na teoria. Segundo Lins (2005), no caso dos médicos, o profissional cuja prática o aprendiz segue não está lá para ensiná-lo a ensinar, e sim para ensiná-lo a fazer (p. 118), visto que o curso possui professores que atuam na área em que os acadêmicos vão trabalhar.

Como seriam os estágios dos alunos da Licenciatura em Matemática, se eles acompanhassem um aluno de perto e soubessem das suas dificuldades, ficassem durante um tempo buscando compreensões de como ele aprende alguns conteúdos, quais seriam suas angústias e realizações na sala de aula de matemática? Uma realidade ainda muito presente nas licenciaturas é o grande distanciamento entre o que se aprende na universidade e o que se trabalha na escola do Ensino Fundamental e Médio.

O curso de Licenciatura em Matemática possui diversos professores que não atuam na área em que os licenciados trabalharão, professores que pouco conhecem as particularidades do contexto escolar, que nunca durante suas vidas acadêmicas (graduação, mestrado e doutorado) entraram em uma sala de aula do sexto ano do Ensino Fundamental como professor. Que ironia pensar que existe um curso que possui um quadro de profissionais que não vivenciaram práticas que formam futuros profissionais. São professores que não estiveram (institucionalmente) nas salas de aula da Educação Básica e estão formando professores para atuarem nesse contexto.

Os futuros professores passam quatro anos na Licenciatura, estudando Cálculo, Álgebra, Geometria, Análise, entre outras disciplinas, aprendendo diversos conteúdos que não serão abordados na Educação Básica. E, às vezes, ouvimos de alguns professores que 
quando eles forem para sala de aula não poderão falar sobre esses conteúdos porque lá os alunos "não vão entender".

Segundo Lins (2005), precisamos estudar possibilidades de transformar os cursos de Matemática em cursos de Educação Matemática (p. 119). Isso não significa que devemos tirar das grades curriculares todas as disciplinas de conteúdo matemático. O grande problema é a forma como essas disciplinas são trabalhadas e organizadas. Não existe um diálogo entre os conteúdos vistos nas licenciaturas e os conteúdos das salas de aula do futuro profissional. Lins (2005) diz que, desde o tempo de sua graduação, defende que o professor

/.../ precisa saber mais, e não menos Matemática, mas sempre esclarecendo que este mais não se refere a mais conteúdo, e sim a um entendimento, uma lucidez maior, e isto inclui, necessariamente, a compreensão de que mesmo dentro da Matemática do matemático produzimos significados diferentes para o que parece ser a mesma coisa (p. 122).

Moreira e David $(2003,2005)$ apresentam alguns conflitos entre a formação matemática que os futuros professores experienciam em suas Licenciaturas e sua futura prática profissional. Esses autores discutem as relações entre os saberes trabalhados nos processos de formação matemática do professor na Licenciatura e os saberes efetivamente mobilizados no exercício profissional docente na escola básica (MOREIRA, DAVID, 2005, p.59).

Esses autores argumentam que os cursos de Licenciatura em Matemática não preparam o licenciando para ensinar os alunos da Educação Básica. Os conteúdos associados à prática docente em sala de aula devem ser abordados na licenciatura, levantando questões que sejam adequadas à forma como serão tratadas na Matemática Escolar, aproximando assim a formação do licenciado e a prática escolar, contribuindo para que haja modificações na prática pedagógica em Matemática.

De acordo com Moreira e David (2005), a articulação do processo de formação na licenciatura com as questões postas pela prática docente escolar, mais do que tentar integrar à prática escolar uma formação específica orientada pela matemática científica, demandaria uma concepção de formação "de conteúdo", que leve em conta a especificidade do destino profissional do licenciado e tome como referência central a matemática escolar.

Fiorentini (2005) também discute as disciplinas de formação pedagógica nas disciplinas matemáticas e também a formação matemática nas disciplinas pedagógicas nos cursos de Licenciatura em Matemática. Em seu artigo, afirma que Shulman (1986) é enfático ao dizer que saber da matemática para ser um matemático não é mesma coisa que saber da matemática para ser professor de matemática. Segundo Fiorentini, Shulman não defende que o licenciando deva ter uma matemática inferior (ou mais simples) que o bacharel. Se, para o bacharel, é suficiente ter um formação técnico-formal da matemática - também chamada de formação sólida da matemática - para o futuro professor isso não basta. Ainda, segundo esse autor

A maioria dos professores de Cálculo, de Álgebra, de Análise, de Topologia, etc, acredita que ensina apenas conceitos e procedimentos matemáticos. /.../ [entretanto eles] ensinam também um jeito de ser pessoa e professor, isto é um modo de conceber e estabelecer relação com o mundo e com a Matemática e seu ensino. /.../ O futuro professor 
não aprende deles apenas uma matemática, internaliza também um modo de concebê-la e de tratá-la e avaliar sua aprendizagem (2005, p. 110-111).

Esses são alguns argumentos que podem levar à superação da dicotomia entre formação específica, em relação ao conteúdo, e formação pedagógica, em relação ao ensino desse conteúdo. É interessante pensar em argumentos desse tipo, pois eles anunciam um horizonte para a construção de um curso de formação de professores, no qual sejam tratadas temáticas a respeito de professores de matemática, e não sobre matemática e, depois, sobre como ensinar matemática.

Por outro lado, Fiorentini afirma que as disciplinas didático-pedagógicas

podem contribuir para alterar a visão e a concepção sobre Matemática, principalmente se o foco passa a ser não mais o conhecimento pronto e acabado, como geralmente aparece em alguns manuais didáticos, mas, o saber em movimento em seu processo de significação e elaboração, tendo a linguagem simbólica como mediadora desse processo de significado (2005, p. 112).

Um fato que pouco é tratado nas Licenciaturas em Matemática é uma discussão das razões e argumentos para que as disciplinas de formação da matemática do matemático (LINS, 2004). Por que Análise Real? Por que Estruturas Algébricas? Parece que sempre foi assim e, como sempre foi, deve ainda continuar (LINS, 2004; VIOLA DOS SANTOS, 2012). O fato é que não há justificativas, pautadas em pesquisas na comunidade em Educação Matemática, para essas disciplinas comporem o curso de licenciatura em matemática. O argumento da tradição e de que essas disciplinas oferecem os fundamentos da matemática escolar, geralmente, são os únicos que são explicitados.

Lins (2005) apresenta um exemplo emblemático para elucidar essa problemática. Ele fala de Euler, um matemático que não sabia nada de Análise, Estruturas Algébricas, Topologia, Representação Geométrica, Pares ordenados de números complexos, Geometria não-euclidiana e muitas outras coisas. E por quê? Simplesmente, porque estas coisas não existiam em sua época! Mas, por outro lado, Euler era hábil em tratar de problemas matemáticos de vários tipos, um bom aplicador de matemática, tinha domínio adequado e fluente. Euler é um ótimo exemplo para desmascarar a farsa da afirmação de que o professor precisa estudar Cálculo e Análise por causa dos fundamentos (LINS, 2005, p. 121).

Esse distanciamento entre os conteúdos da licenciatura em matemática e a Educação Básica provoca nos acadêmicos uma insegurança ainda maior na sua atuação profissional. O acadêmico estuda disciplinas ao longo do curso que muitas vezes não poderá utilizar em sala de aula. E, mesmo assim, depois de formado, ele recebe um diploma que o coloca em posição de trabalho na Educação Básica. E quando este profissional está dentro da sala de aula, muitas vezes, ele não tem condições de aplicar aquilo que prendeu.

Oliveira (2011), em seu trabalho de doutorado, faz uma análise sobre como o conteúdo matemático (as disciplinas de formação matemática) é tratado pelos pesquisadores em Educação Matemática nas investigações sobre a formação de professores de matemática. Para isso, realizou uma revisão bibliográfica nacional em três periódicos: Educação Matemática em Revista, Boletim de Educação Matemática (BOLEMA) e Zetetiké, e também em dissertações, teses e livros com essa temática. Em relação a uma revisão de periódicos internacionais, ela investigou os periódicos Educational Studies in Mathematics (ESM), Jornal Mathematics Teacher Education (JMTE), Zentralblatt für Didaktik der 
Mathematik (ZDM). Como o volume de artigos encontrado foi muito grande, cerca de 421 textos, a autora optou por fazer sua revisão dos artigos internacionais por meio do volume 1 do livro The International Handbook of Mathematics Teacher Education (2008). A partir dessa análise, Oliveira (2011)

apresenta tendo como foco principal a maneira como os autores encaram/enxergam/discutem o conteúdo matemático ou as chamadas disciplinas específicas nos cursos de licenciatura em Matemática (p. 59).

Em sua leitura dos trabalhos (livros, dissertações, teses e artigos, todos em periódicos nacionais), elencou as seguintes temáticas: $1^{\text {a) }}$ Sobre Matemática, seu ensino e aprendizagem: natureza e concepções; $2^{a}$ ) Atitudes e abordagens no como lidar com o conteúdo matemático; $3^{a}$ ) Exploração do conteúdo matemático através de metodologias e do uso de ferramentas; 4a ) Aproximações e discussão de conteúdos em atividades formativas do Professor de Matemática; 5a) Conteúdo matemático, representações e significados; 6a) Pertinência de determinados conteúdos como curriculares.

Notamos que são várias as formas com as quais o conteúdo matemático é problematizado nas pesquisas de autores nacionais. Elas perpassam várias temáticas, desde a natureza da matemática até a pertinência de alguns temas no currículo da Licenciatura. Entretanto, na leitura de Oliveira (2011), os trabalhos, de certa maneira,

identificam-se e reconhecem-se como legítimas e importantes certas formas de conhecimento, distintas das da matemática acadêmica; participa-se da análise e da tematização dos significados da matemática da rua e do desenvolvimento de novos significados, possivelmente matemáticos, que coexistirão com os da rua ("não matemáticos"), sem querer substituí-los; examinam-se permanentemente as inter-relações entre diferentes matemáticas, tendo como parâmetro as relações de poder envolvidas no uso de cada uma delas; toma-se como elemento articulador das disciplinas específicas da licenciatura a prática social do professor de Matemática; elaboram-se seqüências didático-pedagógicas que problematizam as concepções e representações conceituais dos licenciandos sobre conteúdos matemáticos, aprofundando as visões intuitivas dentro da prática docente; desloca-se a importância dada ao conteúdo matemático para os significados para ele produzidos; e, utilizam-se noções (como CPC e conhecimento matemático para ensino) buscando-se compreender como alunos aprendem, como alunos entendem, visando ao aprimoramento da prática docente (2011, p. 106).

Oliveira (2011) também afirma que apesar de serem discutidos vários aspectos que vão além da matemática por ela mesma, os trabalhos, em sua grande maioria, não discutem o conteúdo matemático. Há uma aceitação sem muitos questionamentos em relação às disciplinas de conteúdo matemático na Licenciatura. É preciso que o professor de matemática saiba matemática. É preciso que ele tenha em sua grade curricular as disciplinas de formação matemática... Por quê? Sob quais argumentos? Em que sentido? Estas são perguntas sem sentido de serem formuladas e sem necessidade de serem respondidas, por muitas pessoas. Novamente, vemos que a tradição ainda impera nas discussões sobre a formação matemática do professor de matemática.

Apresentamos uma discussão a respeito das discussões sobre a formação matemática de professores de matemática na Licenciatura. Se, por um lado, temos vários argumentos na direção de transformações estruturais nas grades curriculares das Licenciaturas, por 
outro, temos realidades dos cursos com professores que pouco se importam em refletir sobre suas disciplinas no intuito de formar o futuro professor de matemática para lidar com as demandas matemáticas de sua prática profissional.

\title{
Estratégia Metodológica
}

Neste trabalho, desenvolvemos uma pesquisa qualitativa, visto a natureza dos nossos dados e dos nossos objetivos. A pesquisa qualitativa tem como foco entender e interpretar dados e discursos. Concordamos com a caracterização de Garnica (2004), para pesquisa qualitativa, sendo que, a partir dela, estruturamos nosso trabalho.

\begin{abstract}
Segundo minha concepção, o adjetivo "qualitativa" estará adequado às pesquisas que reconhecem: (a) a transitoriedade de seus resultados; (b) a impossibilidade de uma hipótese a priori, cujo objetivo da pesquisa será comprovar ou refutar; (c) a não neutralidade do pesquisador que, no processo interpretativo, se vale de suas perspectivas e filtros vivenciais prévios dos quais não consegue se desvencilhar; (d) que a constituição de suas compreensões dá-se não como resultado, mas numa trajetória em que essas mesmas compreensões e também os meios de obtê-las podem se (re)configurados; (e) a impossibilidade de estabelecer regulamentações, em procedimentos sistemáticos, prévios, estáticos e generalistas (GARNICA, 2006, p. 88).
\end{abstract}

Produzimos nossos dados por meio de dois Projetos Políticos Pedagógicos de dois cursos de Licenciatura em Matemática na modalidade a distância. Analisamos, a partir de leituras desses PPPs, características de propostas de formação matemática para futuros professores de matemática. Os PPPs escolhidos foram o da Universidade Federal do Rio Grande do Sul (UFRGS) e da Pontifícia Universidade Católica de São Paulo (PUC-SP).

Essa investigação tinha como pano de fundo um projeto maior, intitulado "Mapeamento do currículo prescrito em alguns cursos de licenciatura em matemática, no Brasil, no período de 2010 a 2012" ${ }^{\prime}$, que, entre outros objetivos, tinha o de investigar currículos prescritos de cursos de Licenciatura em Matemática que obtiveram conceito 4 e 5 no ENADE, no período de 2010 a 2012. Os dois cursos que analisamos neste trabalho obtiveram nota 4 ou 5 no ENADE, nos currículos prescritos na modalidade presencial.

Neste artigo, apresentamos nossas análises focadas nas discussões da formação matemática dos futuros professores de matemática, por meio dos PPPs.

\section{Uma leitura dos PPPs}

Apresentamos a seguir nossas análises sobre os Currículos prescritos das Licenciaturas em Matemática investigadas. Faremos considerações a respeito do Currículo prescrito da UFRGS e depois da PUC-SP.

\section{Currículo Prescrito da UFRGS}

O Projeto Político Pedagógico do Curso de Licenciatura em Matemática da UFRGS, na modalidade a distância, é o mesmo de outras cinco universidades (FURG, UERGS, UNISC,

\footnotetext{
${ }^{6}$ Projeto aprovado no edital MCT/CNPq/MEC/CAPES N o 02/2010 (Processo 401117/2010-3).
} 
UFRGS, UFSM) do Rio Grande do Sul que compõem a Rede Gaúcha de Ensino Superior a Distância (REGESD).

O PPP do curso de Licenciatura em Matemática da UFRGS na modalidade à distância destina-se a professores em exercício nas redes públicas de ensino nos anos finais do Ensino Fundamental e/ou do Ensino Médio, sem a formação específica e que estejam exercendo a docência em Matemática. Um dos objetivos do curso é oferecer uma possibilidade de formação superior em Licenciatura em Matemática, em regiões do Estado do Rio Grande do Sul que não contam com cursos em nível universitário. O curso da UFRGS EAD possui carga horária total de 2.930 horas e duração de oito semestres. As aulas acontecem por meio da plataforma virtual e encontros presenciais. Analisamos o PPP da UFRGS, na modalidade à distância, do ano de 2007 (ver tabela 1).

\begin{tabular}{|c|c|c|}
\hline $\begin{array}{l}\text { ATIVIDADE } \\
\text { DE ENSINO }\end{array}$ & COMPONENTES CURRICULARES & $\begin{array}{c}\text { CARGA } \\
\text { HORÁRIA }\end{array}$ \\
\hline \multirow{6}{*}{ ETAPA I } & Matemática e Realidade & 60 \\
\hline & Sistemas Numéricos & 60 \\
\hline & Instrumentalização para EaD & 60 \\
\hline & História e Organização da Educação Brasileira & 45 \\
\hline & Seminário Integrador I & 60 \\
\hline & TOTAL DA ETAPA & 285 \\
\hline \multirow{7}{*}{ ETAPA II } & Funções e Aplicações & 60 \\
\hline & Geometria Plana & 60 \\
\hline & Sociologia da Educação & 45 \\
\hline & Gestão da Escola e Planejamento Educacional & 60 \\
\hline & Instrumentalização para o acesso à Informação & 60 \\
\hline & Seminário Integrador II & 60 \\
\hline & TOTAL DA ETAPA & 345 \\
\hline \multirow{6}{*}{ ETAPA III } & Cálculo e Aplicações I & 60 \\
\hline & Geometria Analítica no Plano & 60 \\
\hline & Tecnologias Digitais na Educação Matemática & 60 \\
\hline & Filosofia da Educação & 45 \\
\hline & Seminário Integrador III & 60 \\
\hline & TOTAL DA ETAPA & 285 \\
\hline \multirow{7}{*}{ ETAPA IV } & Cálculo e Aplicações II & 60 \\
\hline & Geometria Espacial e Medidas & 60 \\
\hline & Matemática Discreta & 60 \\
\hline & Psicologia da Educação & 60 \\
\hline & Teoria do Conhecimento e Epistemologia & 45 \\
\hline & Seminário Integrador IV & 60 \\
\hline & TOTAL DA ETAPA & 345 \\
\hline \multirow{6}{*}{ ETAPA V } & Cálculo e Aplicações III & 60 \\
\hline & Geometria Analítica no Espaço & 60 \\
\hline & Fenômenos Físicos I & 60 \\
\hline & Inclusão Social e Cidadania & 45 \\
\hline & Seminário Integrador $\vee$ & 60 \\
\hline & TOTAL DA ETAPA & 285 \\
\hline \multirow{4}{*}{ ETAPA VI } & Introdução à Álgebra Linear & 60 \\
\hline & Estatística & 60 \\
\hline & Fenômenos Físicos II & 60 \\
\hline & Seminário Integrador VI & 45 \\
\hline
\end{tabular}




\begin{tabular}{|l|l|c|}
\hline \multirow{4}{*}{ ETAPA VII } & Estágio Supervisionado I - Ensino Fundamental & 210 \\
\cline { 2 - 3 } & TOTAL DA ETAPA & 435 \\
\hline \multirow{4}{*}{ ETAPA VIII } & Algebra & 60 \\
\cline { 2 - 3 } & Matemática das Aproximações & 60 \\
\cline { 2 - 3 } & Aplicações da Matemática & 60 \\
\cline { 2 - 3 } & Seminário Integrador VII & 45 \\
\cline { 2 - 3 } & Estágio Supervisionado II - Ensino Médio & 210 \\
\cline { 2 - 3 } & TOTAL DA ETAPA & 435 \\
\hline \multirow{5}{*}{} & Pesquisa em Educação Matemática & 60 \\
\cline { 2 - 3 } & História da Matemática & 60 \\
\cline { 2 - 3 } & Tópicos de Análise & 60 \\
\cline { 2 - 3 } & Seminário Integrador VII & 45 \\
\cline { 2 - 3 } & Trabalho de Conclusão de Curso & 315 \\
\cline { 2 - 3 } & TOTAL DA ETAPA & 2.730 \\
\hline & & 200 \\
\hline & Atividades Complementares de Graduação & 2.930 \\
\hline & & \\
\hline
\end{tabular}

Segundo o PPP da UFRGS, a dinâmica do curso se constitui na direção de atitudes investigativa, reflexiva e crítica, tanto dos docentes como dos discentes. A partir do perfil dos alunos e dos professores em exercício, os docentes oferecem desde o primeiro ano,

/.../ uma formação que integra as experiências que os professores trazem da sala de aula, bem como questionamentos e problemas ainda em aberto. Tem-se como princípio que é no contínuo processo de reflexãoação-reflexão, junto com a formação matemática que está acontecendo concomitantemente, que pode mudar a situação de sala de aula no que diz respeito, principalmente, a qualidade do ensino. Boas experiências serão aproveitadas e aprimoradas; situações problemáticas serão discutidas, tudo de forma a sustentar as propostas para novas práticas pedagógicas, novos recursos e novas metodologias (PPP, UFRGS, p. 14).

Há indícios de que a proposta de formação nesse curso tenha como ponto de partida a prática profissional dos alunos que já atuam na Educação Básica. Um possível delineamento para as atividades desse curso seria 0 de relacionar as discussões matemáticas das disciplinas de matemática acadêmica com discussões matemáticas das temáticas da matemática escolar. Ao mesmo tempo em que os licenciandos aprenderiam novos conceitos, também poderiam reconstruir ideias, conceitos e procedimentos matemáticos da Educação Básica. Ao mesmo tempo em que eles se debruçariam sobre processos axiomáticos, abstratos da matemática acadêmica, poderiam (re)construir seus conhecimentos em relação aos conceitos menos rigorosos, com mais apelo a relações físicas e "concretas", da matemática escolar. O olhar para a matemática, nessa perspectiva, seria abrangente, tomando a matemática acadêmica e escolar como um todo, como também explicitando suas relações e especificidades.

\section{Currículo Prescrito da PUC-SP}

O PPP do curso de Licenciatura em Matemática da PUC/SP, na modalidade a distância, destina-se preferencialmente a professores em exercício nas redes públicas de ensino nos anos finais do Ensino Fundamental e/ou do Ensino Médio, sem a formação específica. Um dos objetivos do curso é oferecer uma possibilidade de formação superior em Licenciatura em Matemática, em regiões do Estado de São Paulo que não contam com cursos em nível 
universitário. O curso da PUC/SP EAD possui carga horária total de 2.952 horas e tem duração de seis semestres. As aulas acontecem por meio da plataforma virtual e encontros presenciais. Analisamos o PPP da PUC/SP, na modalidade a distância, do ano de 2007 (tabela 2).

\begin{tabular}{|c|c|c|}
\hline PERÍODOS & IDENTIFICAÇÃO & $\begin{array}{l}\text { CARGA } \\
\text { HORÁRIA }\end{array}$ \\
\hline \multirow{10}{*}{$\begin{array}{l}\text { PRIMEIRO } \\
\text { PERÍODO }\end{array}$} & Funções e Limites & 67 \\
\hline & Matemática, Sociedade e Cultura & 33 \\
\hline & Educação e Cultura & 33 \\
\hline & Geometria Euclidiana Espacial & 67 \\
\hline & Fundamentos da Educação: Desafios da Educação Brasileira & 67 \\
\hline & Aritmética e Álgebra & 67 \\
\hline & Leitura e Produção de Textos & 33 \\
\hline & Introdução da Matemática com a Física: Mecânica & 33 \\
\hline & Atividades Complementares 1 & 33 \\
\hline & SUBTOTAL & 433 \\
\hline \multirow{10}{*}{$\begin{array}{l}\text { SEGUNDO } \\
\text { PERÍODO }\end{array}$} & Funções e Continuidade & 67 \\
\hline & Educação Matemática e TIC & 33 \\
\hline & Educação Matemática e Currículos & 33 \\
\hline & Geometria Euclidiana Plana & 67 \\
\hline & $\begin{array}{l}\text { Fundamentos da Educação: Concepções Teóricas da Educação e Problemas } \\
\text { da Educação }\end{array}$ & 67 \\
\hline & Teoria Elementar dos Números & 67 \\
\hline & Leitura e Produção de Textos de divulgação científica & 33 \\
\hline & Introdução da Matemática com a Física: Óptica & 33 \\
\hline & Atividades Complementares 2 & 33 \\
\hline & SUBTOTAL & 433 \\
\hline \multirow{10}{*}{$\begin{array}{l}\text { TERCEIRO } \\
\text { PERIOODO }\end{array}$} & Geometria Analítica no Plano & 67 \\
\hline & Educação Matemática e suas Investigações EF & 33 \\
\hline & Educação Matemática e suas Investigações EM & 33 \\
\hline & Introdução ao Cálculo Diferencial e Integral & 84 \\
\hline & Projeto Pedagógico e Gestão & 33 \\
\hline & Conhecimento Pedagógico e Docência & 33 \\
\hline & Estruturas Algébricas: Anéis e Corpos & 67 \\
\hline & Introdução ao Pensamento Teológico & 50 \\
\hline & Atividades Complementares 3 & 33 \\
\hline & SUBTOTAL & 433 \\
\hline \multirow{13}{*}{$\begin{array}{l}\text { QUARTO } \\
\text { PERÍODO }\end{array}$} & Geometria Analítica no Espaço & 67 \\
\hline & Educação Inclusiva & 33 \\
\hline & Gestão do Trabalho Pedagógico na sala de aula de Matemática & 33 \\
\hline & Cálculo Diferencial & 67 \\
\hline & Didática e Metodologia de Ensino & 33 \\
\hline & Introdução ao Pensamento Teológico 2 & 50 \\
\hline & Introdução à Álgebra Linear & 67 \\
\hline & Introdução à Metodologia de Pesquisa para o TCC & 50 \\
\hline & Análise exploratória de dados & 67 \\
\hline & Supervisão de estágio 1 & 22 \\
\hline & Estágio em Campo 1 & 77 \\
\hline & Atividades Complementares 4 & 33 \\
\hline & SUBTOTAL & 599 \\
\hline
\end{tabular}




\begin{tabular}{|c|c|c|}
\hline \multirow{13}{*}{$\begin{array}{l}\text { QUINTO } \\
\text { PERÍODO }\end{array}$} & Geometria das Transformações & 50 \\
\hline & Geometrias não Euclidianas & 33 \\
\hline & Planejamento e Políticas Públicas Educacionais & 33 \\
\hline & Orientação do TCC (fase 1) & 17 \\
\hline & Educação Matemática no Ensino Fundamental & 67 \\
\hline & Álgebra Linear & 67 \\
\hline & Cálculo Integral & 67 \\
\hline & Análise Combinatória & 33 \\
\hline & Métodos Estatísticos & 33 \\
\hline & Supervisão de estágio 2 & 17 \\
\hline & Desenvolvimento do TCC (fase1) & 34 \\
\hline & Estágio em Campo 2 & 67 \\
\hline & SUBTOTAL & 519 \\
\hline \multirow{14}{*}{$\begin{array}{c}\text { SEXTO } \\
\text { PERÍODO }\end{array}$} & Tópicos de Análise Real & 67 \\
\hline & Cálculo de Probabilidades & 33 \\
\hline & Interfaces da Matemática com a Economia & 33 \\
\hline & Orientação do TCC (fase 2) & 17 \\
\hline & Educação Matemática no Ensino Médio & 67 \\
\hline & Geometria Euclidiana Axiomática & 67 \\
\hline & Libras & 33 \\
\hline & Introdução à Teoria dos Grupos & 67 \\
\hline & Educação Matemática na EJA & 33 \\
\hline & Supervisão de estágio 3 & 17 \\
\hline & Desenvolvimento do TCC (fase2) & 34 \\
\hline & Estágio em Campo 3 & 67 \\
\hline & SUBTOTAL & 535 \\
\hline & TOTAL & 2.952 \\
\hline
\end{tabular}

Notamos, nesse PPP, uma reflexão a respeito da formação matemática oferecida nesses cursos, tomando como ponto de partida a prática profissional do professor. De acordo com o PPP,

A avaliação diagnóstica dos cursos de Matemática, em especial, das experiências de formação de professores de Matemática na PUC/SP vem sendo realizada, ao longo dos últimos anos, pelo corpo docente e coordenação do Curso de Matemática, buscando respostas consistentes para perguntas tais como: Que Matemática precisa saber um futuro professor de Matemática? Como deve aprender Matemática, aquele que, num futuro próximo, se dedicará a ensiná-la, profissionalmente? Como conseguir que os futuros professores se tornem competentes no processo de transformar os conhecimentos matemáticos historicamente produzidos em saber matemático escolar relevante à formação intelectual dos alunos? Como provocar, desenvolver e sustentar um processo de reconversão epistemológica que permita aos futuros professores se libertarem de comportamentos, atitudes e crenças que têm contribuído para estigmatizar a Matemática? (PPP, PUC, p. 15)

É interessante notar que, em documento oficial de um curso de Licenciatura em Matemática, há a pergunta "Que Matemática precisa saber um futuro professor de Matemática?", que se coloca como centro de várias pesquisas desenvolvidas em diferentes partes do mundo na área de formação (matemática) de professores de Matemática (BALL, BASS, 2003; ROWLAND, 2008; LINS, 2006). A presença desse tipo de questionamento, de certa forma, anuncia perspectivas de mudanças para a formação matemática de professores 
de matemática da Educação Básica, visto que há uma reflexão de que as demandas da prática profissional dos professores requerem outra formação matemática.

Um ponto de destaque em relação aos dois PPPs foi a presença da ideia de Resolução de Problemas como algo fundamental nas disciplinas. Esse termo é mencionado nos objetivos gerais e/ou específicos de várias disciplinas. No PPP da PUC, quinze disciplinas mencionam a "resolução de problemas" e no PPP da UFRGS são oito disciplinas. Entretanto, as afirmações que envolvem a expressão resolução de problemas aparecem na direção de possibilitar que os alunos resolvam problemas como meio para tematizar os conteúdos das disciplinas. Entretanto, poucas explicações são apresentadas nas ementas e programas sobre a forma como isso será desenvolvido.

\section{Algumas Considerações}

Nossas análises indicam a presença de reflexões a respeito de qual matemática é necessária ou adequada para o futuro professor de matemática. Claro que o fato de o PPP apresentar algumas discussões, das quais inferimos essa afirmação, não nos garante que isso se operacionalize na prática dos docentes desse curso. O que queremos ressaltar é que nos documentos oficiais de cursos de Licenciatura em Matemática, na modalidade a distância, há uma preocupação em relação à formação matemática dos futuros professores e que esse fato oferece possibilidades de que outras propostas possam ser construídas, tomando como referência as demandas do trabalho profissional de professores de matemática da Educação Básica.

Outro ponto que podemos destacar em relação aos PPPs são as intenções de se articular os domínios de conhecimentos pedagógico e matemático nas disciplinas do curso. Inferimos que nos cursos de Licenciatura em Matemática, na modalidade a distância, pode estar ocorrendo mudanças nas maneiras de os docentes encararem a formação do futuro professor, o que não ocorre de maneira dicotômica, matemática mais pedagogia, mas sim de uma maneira articulada e sistemática.

Investigar como essas ideias propostas em documentos oficiais, os Projetos Político Pedagógico, são implementadas é um desafio para pesquisadores interessados nessa temática. Entender as diferenças entre os PPPs dos cursos presenciais e dos cursos a distâncias também se apresenta como algo a ser analisado. Nossas discussões, neste artigo, focaram nas propostas de formação matemática em cursos de Licenciatura em Matemática, na modalidade a distância, que foram elaborados recentemente e que talvez ofereçam possibilidades e condições de outras estruturações para o currículo dos cursos, mais próximas das discussões apontadas por pesquisadores que apresentamos.

Superar a lógica de que aprender matemática do matemático (LINS, 2004) implica em compreender os fundamentos da matemática escolar e estar apto para atuar na Educação Básica é ainda o desafio, mesmo que, em algumas discussões, como as que foram feitas aqui, vislumbre-se uma direção de mudanças. 


\section{Referências}

BALL, D. L.; BASS, H. Toward practice-based theory of mathematical knowledge for teaching. In: B. Davis.; E. Smith (Eds). Proceedings of the 2002 Annual Meeting of the Canadian Mathematics Education Study Group, Edmonton, 2003. Edmonton. Proceedings... Edmonton: CMESG/GCEDM, 2003, p. 3-14.

BRASIL. Parecer CNE/CES 1.302/2001, de 06 de novembro de 2001. Estabelece as Diretrizes Curriculares Nacionais para os Cursos de Matemática, Bacharelado e Licenciatura. Diário Oficial da União, Poder Executivo, Brasília, DF, 5 mar. 2002a. Seção 1, p. 15.

GARNICA, A. V. M. História Oral e Educação Matemática. In: Pesquisa Qualitativa em Educação Matemática. BORBA, M. C.; ARAUJO, J. L. (orgs.) Belo Horizonte: Autêntica, 2004.

LINS, R. C. Characterizing the mathematics of the mathematics teacher from the point of view of meaning production. In: 10th International Congress on Mathematical Education, Copenhagen, 2004. Copenhagen. Proceedings... Plenary and Regular Lectures, 2006, p. 1-16.

LINS, R. C. A Formação Pedagógica em Disciplinas de Conteúdo Matemático nas Licenciaturas em Matemática. $\quad$ Revista de Educação PUC-Campinas. n. 10; pp. 117-123. 2005.

MOREIRA, P. C.; DAVID, M. M. M. S. Matemática escolar, matemática científica, saber docente e formação de professores. Zetetike, Campinas, v.11, n.19, p. 57-80, 2003.

MOREIRA, P. C.; DAVID, M. M. M. S. A formação matemática do professor: licenciatura e prática docente. Belo Horizonte: Autêntica, 2005.

OLIVEIRA, V. A. Uma leitura sobre formação continuada de professores de matemática fundamentada em uma categoria da vida cotidiana. 2011. Tese (Doutorado em Educação Matemática) - Instituto de Geociências e Ciências Exatas, Universidade Estadual Paulista, Rio Claro. 2011.

PROJETO POLÍTICO PEDAGÓGICO (PPP). Universidade Federal do Rio Grande do Sul, 2007.

PROJETO POLÍTICO PEDAGÓGICO (PPP). Pontifícia Universidade Católica de São Paulo, 2007.

ROWLAND, T. Researching teachers' mathematics disciplinary knowledge. In P. Sullivan and T. Wood (Eds.) International handbook of mathematics teacher education: vol.1. Knowledge and beliefs in mathematics teaching and teaching development. Rotterdam: Sense Publishers, p. 273-298, 2008

VIOLA DOS SANTOS, J. R. Legitimidades possíveis para a Formação Matemática de Professores de Matemática. 2012. Tese (Doutorado em Educação Matemática) - Instituto de Geociências e Ciências Exatas, Universidade Estadual Paulista, Rio Claro, 2012. 